\title{
Variation of soil hydraulic properties with alpine grassland degradation in the eastern Tibetan Plateau
}

\author{
Tao Pan ${ }^{1,3}$, Shuai Hou ${ }^{1,2}$, Shaohong Wu ${ }^{1}$, Yujie Liu ${ }^{1}$, Yanhua Liu ${ }^{1}$, Xintong Zou ${ }^{1,2}$, Anna Herzberger ${ }^{3}$, and \\ Jianguo Liu $^{3}$ \\ ${ }^{1}$ Key Laboratory of Land Surface Pattern and Simulation, Institute of Geographic Sciences and Natural Resources Research, \\ Chinese Academy of Sciences, Beijing, 100101, China \\ ${ }^{2}$ University of the Chinese Academy of Sciences, Beijing, 100049, China \\ ${ }^{3}$ Center for Systems Integration and Sustainability, Department of Fisheries and Wildlife, Michigan State University, \\ East Lansing, MI 48824, USA
}

Correspondence to: Yujie Liu (liuyujie@igsnrr.ac.cn)

Received: 1 July 2016 - Discussion started: 1 August 2016

Revised: 31 March 2017 - Accepted: 4 April 2017 - Published: 2 May 2017

\begin{abstract}
Ecosystems in alpine mountainous regions are vulnerable and easily disturbed by global environmental change. Alpine swamp meadow, a unique grassland type in the eastern Tibetan Plateau that provides important ecosystem services to the upstream and downstream regions of international rivers of Asia and other parts of the world, is undergoing severe degradation, which can dramatically alter soil hydraulic properties and water cycling processes. However, the effects of alpine swamp meadow degradation on soil hydraulic properties and the corresponding influencing mechanisms are still poorly understood. In this study, soil moisture content (SMC), field capacity (FC) and saturated hydraulic conductivity $\left(K_{\mathrm{S}}\right)$ together with several basic soil properties under lightly degraded (LD), moderately degraded (MD) and severely degraded (SD) alpine swamp meadow were investigated; the variations in $\mathrm{SMC}, \mathrm{FC}$ and $K_{\mathrm{s}}$ with alpine swamp meadow degradation and their dominant influencing factors were analysed. The results showed that SMC and FC decreased consistently from LD to SD, while $K_{\mathrm{s}}$ decreased from $\mathrm{LD}$ to $\mathrm{MD}$ and then increased from MD to SD, following the order of $\mathrm{LD}>\mathrm{SD}>\mathrm{MD}$. Significant differences in soil hydraulic properties between degradation degrees were found in the upper soil layers $(0-20 \mathrm{~cm})$, indicating that the influences of degradation were most pronounced in the topsoils. FC was positively correlated with capillary porosity, water-stable aggregates, soil organic carbon, and silt and clay content; $K_{\mathrm{S}}$ was positively correlated with non-capillary porosity (NCP). Relative to other soil properties, soil poros-
\end{abstract}

ity is the dominant factor influencing FC and $K_{\mathrm{s}}$. Capillary porosity explained $91.1 \%$ of total variance in FC, and NCP explained $97.3 \%$ of total variance in $K_{\mathrm{s}}$. The combined effect of disappearing root activities and increasing sand content was responsible for the inconsistent patterns of NCP and $K_{\mathrm{s}}$. Our findings suggest that alpine swamp meadow degradation would inevitably lead to reduced water holding capacity and rainfall infiltration. This study provides a more comprehensive understanding of the soil hydrological effects of vegetation degradation. Further hydrological modelling studies in the Tibetan Plateau and similar regions are recommended to understand the effects of degraded alpine swamp meadows on soil hydraulic properties.

\section{Introduction}

Soil moisture plays a critical role in land surface processes and hydrological cycles. It not only directly participates in soil hydrological processes but also influences vegetation growth and even modifies weather processes and local climate (Legates et al., 2011; Shein, 2010; Vereecken et al., 2015). Field capacity (FC) and saturated hydraulic conductivity $\left(K_{\mathrm{s}}\right)$ are two key soil hydraulic properties that jointly affect soil water storage, transmission and distribution (Cassel and Nielsen, 1986; Marshall et al., 2014). Knowledge of how $\mathrm{FC}$ and $K_{\mathrm{s}}$ vary and of their influencing factors is essential for a better understanding of soil hydrological processes. 
FC and $K_{\mathrm{S}}$ are also key parameters in most hydrological, climate and land surface models (Boluwade et al., 2013; Reszler and Fank, 2016; Tatsumi and Yamashiki, 2015). Therefore, understanding the effects of vegetation changes on FC and $K_{\mathrm{S}}$ is necessary for model parameterization and for reducing the uncertainty of simulations (Sun et al., 2016).

Soil hydraulic properties are highly heterogeneous both spatially and temporally and could respond swiftly to external changes and disturbances (Ma et al., 2016; Strudley et al., 2008). FC and $K_{\mathrm{S}}$ are mainly influenced by vegetation, soil (Pachepsky and Park, 2015), topography (Leij et al., 2004), climate (Jarvis et al., 2013) and human activities (Mubarak et al., 2009; Palese et al., 2014). In recent years, vegetation degradation has been widespread because of natural environmental changes and anthropogenic influences. Efforts have been devoted to revealing the effects of vegetation degradation on soil hydraulic properties across scales and ecosystem types. For forest, Lal (1996), Niemeyer et al. (2014), and Zimmermann and Elsenbeer (2008) analysed the variations in $K_{\mathrm{S}}$ along gradients of disturbance and confirmed the increasing trend of $K_{\mathrm{S}}$ with forestation processes. Krummelbein et al. (2009) investigated the effects of grazing intensity on soil hydraulic properties and revealed the variations in soil porosity and soil retention characteristics in Inner Mongolian grasslands. Recently, Fu et al. (2015) and Price et al. (2010) explored the variations in $K_{\mathrm{S}}$ with land use changes and demonstrated the decrease in $K_{\mathrm{s}}$ and the subsequent increase in overland flow resulting from deforestation or cultivation. Despite these advances, existing studies mostly focused on low-altitude areas. There are still many other regions where the effects of vegetation degradation on soil hydraulic properties are inadequately studied (Vereecken et al., 2015). This is highlighted in remote areas such as alpine mountainous regions; these are cold and adverse environments, where fieldwork is time-consuming and extremely labour-intensive (Bernhardt et al., 2014; Wang et al., 2012).

Alpine mountainous regions are widely distributed around the world, such as the Rocky Mountains in North America, the Andean mountain range in South America, the Alps in Europe, Mount Kilimanjaro in Africa, the Himalayans in Tibet and Mount Fuji in Japan. These regions are often the headwaters of great rivers and supply a large amount of water to the lower reaches (Bernhardt et al., 2014; Kormann et al., 2015). Alpine grassland is one of the main ecosystem types that plays an important role in water supply service of these regions. Because of the extreme environmental conditions of alpine mountainous regions, the alpine ecosystems are very vulnerable to environmental change. Because of global climate warming and human disturbances, alpine grasslands are experiencing intense changes generally leading to degradation, which can have great influence on soil hydrological processes. Therefore, understanding the responses of soil hydraulic properties to alpine grassland variations is of great importance (Laghari et al., 2012). For example, in central Nepal, south of the Himalayas, Ghimire et al. (2014) and
Prasad et al. (2013) investigated variations in $K_{\mathrm{S}}$ with land use changes and found that reforestation of degraded pasture could substantially increase $K_{\mathrm{S}}$ in surface and subsurface layers. Leitinger et al. (2010) studied FC and soil infiltration rate of alpine pasture in the Alps and found that grazing significantly decreased FC and soil infiltration rate in the $0-20 \mathrm{~cm}$ layer, and thus altered surface runoff generation. In the Tibetan Plateau, Wang et al. (2012) confirmed that changes in alpine grassland vegetation cover will greatly alter infiltration processes and hill slope runoff coefficients. Although these studies contributed to a better understanding of the effect of alpine ecosystem variations on soil hydraulic properties, they primarily addressed the change patterns of hydraulic properties. Moreover, it has been confirmed that soil physical and chemical properties, such as soil porosity, texture and organic matter content, are closely connected with soil hydraulic properties (Fu et al., 2015; Jarvis et al., 2013; Strudley et al., 2008). However, studies about the quantitative relationships between soil hydraulic properties and physicochemical properties are still relatively limited.

Widely known as "the third pole" and the highest place in the world, the Tibetan Plateau is the headwaters region of the Yangtze, Yellow and Mekong rivers, which are the world's third, fifth and seventh longest rivers, respectively. The hydrological cycling of this region has great influence on the energy and water processes of eastern Asia. Because of climate change, overgrazing, human activities and rodents, alpine meadow on the Tibetan Plateau has been severely degraded (Wang et al., 2007). Although hydrological effects of alpine meadow degradation over the Tibetan Plateau have been extensively explored (Li et al., 2012; Wang et al., 2007, 2010; Zeng et al., 2013), large discrepancies still exist in the conclusions obtained. For example, Zeng et al. (2013) analysed the effect of alpine meadow degradation on soil hydraulic properties using tension infiltrometers in the centre of the Tibetan Plateau and found that $K_{\mathrm{S}}$ generally decreased with degradation for both $0-10$ and $40-50 \mathrm{~cm}$ layers; Wei et al. (2010) investigated the impact of alpine meadow degradation on soil infiltration by double-ring infiltrator in the eastern Tibetan Plateau and reported that $K_{\mathrm{S}}$ of the 0 $20 \mathrm{~cm}$ layer decreased initially and then increased. Wang et al. (2007) measured $K_{\mathrm{S}}$ of alpine steppe and alpine meadow at the source of the Yangtze River and found that $K_{\mathrm{S}}$ of the surface layers increased significantly with degradation. Yi et al. (2012) reported that FC of the 0-20 cm layer was highest for non-degraded alpine meadow while Li et al. (2012) found that the highest value of FC occurred with light degradation. These inconsistencies showed the high variability of soil hydraulic properties on the Tibetan Plateau and called for further investigations. To date, however, comparison of different change patterns of previous studies and the underlying mechanisms are rarely reported. As the main grassland type in the eastern Tibetan Plateau, alpine swamp meadow has unique terrestrial-aquatic soil and vegetation characteristics (Shang et al., 2013; Zedler and Kercher, 2005). However, 

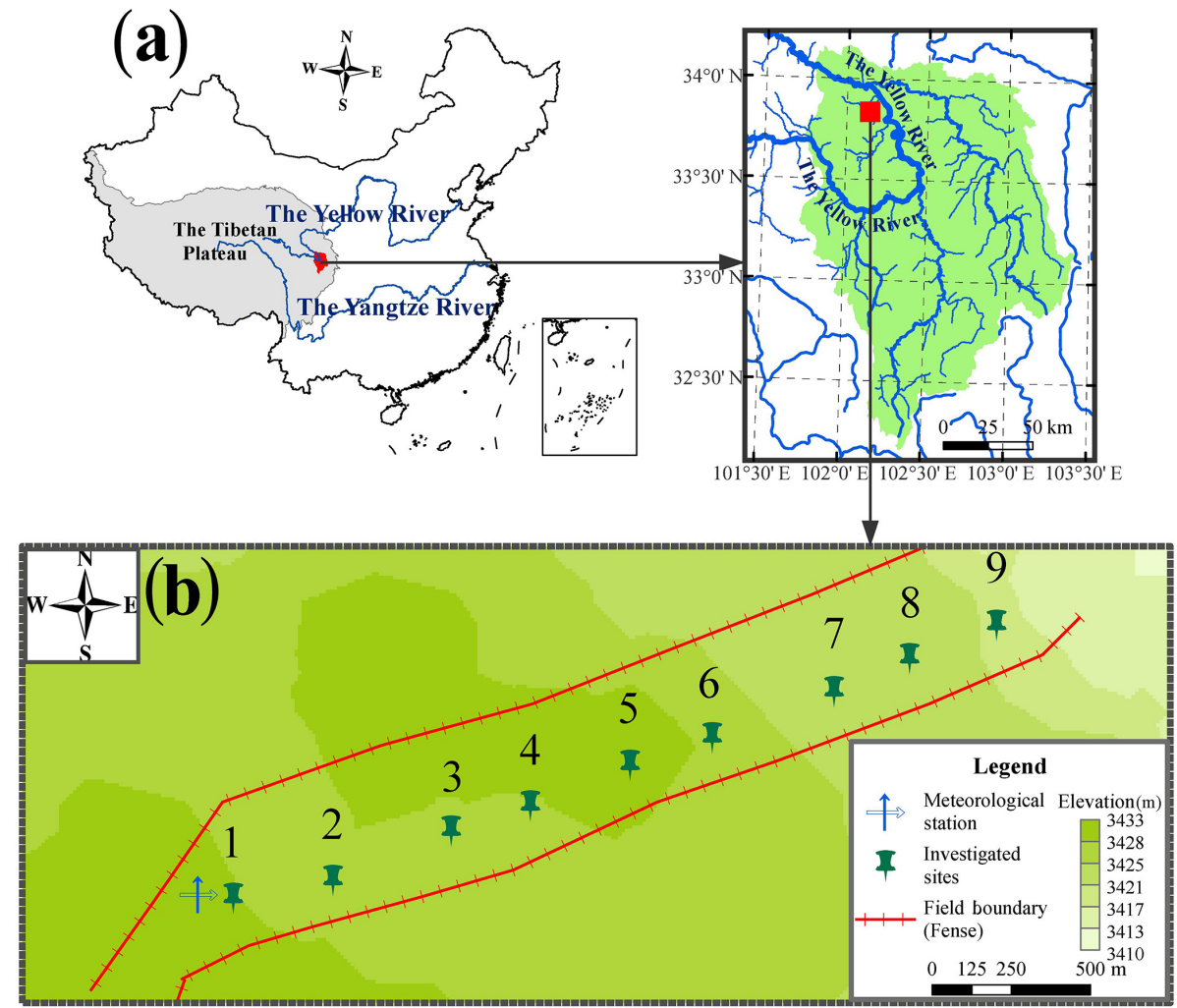

Figure 1. Location of the study area and investigated sites: (a) location of the experimental field in the Zoigê wetland in the east of the Tibetan Plateau, China; (b) distribution of investigated sites within the experimental fields.

little attention has been paid to the effects of alpine swamp meadow degradation on soil hydraulic properties and the influencing mechanisms, which might serve as a bottleneck for a thorough understanding of the hydrological effects of alpine grassland degradation on the Tibetan Plateau.

In this study, we measured $K_{\mathrm{S}}$ and FC along with several key basic soil properties based on a series of experimental sites that represent the degradation process of alpine swamp meadow in the eastern Tibetan Plateau. Several statistical methods such as redundancy analysis were used to quantitatively analyse the variation in soil hydraulic properties and its influencing factors. This study aims to (1) investigate changes in FC and $K_{\mathrm{S}}$ associated with degradation, and (2) analyse the dominant factors and reveal the influencing mechanism of degradation on FC and $K_{\mathrm{s}}$ for alpine swamp meadow.

\section{Material and methods}

\subsection{Site description}

The experimental field $\left(33^{\circ} 46^{\prime} 28^{\prime \prime} \mathrm{N}, 102^{\circ} 12^{\prime} 45^{\prime \prime} \mathrm{E}\right.$, $3435 \mathrm{~m}$ a.s.l. - above sea level) is located in the Zoigê wetland to the east of the Tibetan Plateau (Fig. 1a). This region contains the largest area of alpine swamp in China and is the main recharge area of the Yellow River (Bai et al., 2013). In recent decades, however, a large proportion of wetland area has been converted from swamp to meadow, which in some cases has resulted in desertification (Hu et al., 2015). The mean daily air temperature is $1.2^{\circ} \mathrm{C}$, ranging from $-10.7^{\circ} \mathrm{C}$ in January to $11.7^{\circ} \mathrm{C}$ in July, and the average annual precipitation is $620 \mathrm{~mm}, 85 \%$ of which falls during the summer. The main vegetation is Kobresia-dominated alpine meadow (e.g. Kobresia tibetica, Blysmus sinocompressus, Carex muliensis and others) and the corresponding soil is silt loam, an alpine meadow soil type (Huo et al., 2013).

The experimental field is relatively flat with no perceivable slope and an elevation difference of $20 \mathrm{~m}$ between the highest and lowest points (Fig. 1b). Because of variation in grazing intensity, rodent activities and topographic conditions, patches of grassland showing evidence of initial degradation to almost complete barrenness have emerged across the field, making it possible to choose sites in various degrees of degradation in small areas without large-scale soil spatial heterogeneity confounding the results.

Based on the survey of herbage growth and dominant species, a total of nine investigated sites representing various degrees of degradation were selected along the strip of the enclosed experimental field (Fig. 1b) using a strat- 
Table 1. Vegetation characteristics of investigated sites in this study.

\begin{tabular}{lcrl}
\hline $\begin{array}{l}\text { Degradation } \\
\text { degree }\end{array}$ & $\begin{array}{c}\text { VC } \\
(\text { mean } \pm \\
\left.\mathrm{SD}^{*}, \%\right)\end{array}$ & $\begin{array}{c}\text { Number } \\
\text { of species }\end{array}$ & Dominant species \\
\hline $\mathrm{LD}$ & $80.5 \pm 4.9$ & $18-25$ & $\begin{array}{l}\text { Kobresia tibetica, } \\
\text { Kobresia humilis, } \\
\text { Stipa aliena }\end{array}$ \\
\hline $\mathrm{MD}$ & $59.7 \pm 4.5$ & $15-20$ & $\begin{array}{l}\text { Kobresia pygmaea, } \\
\text { Agropyron cristatum, } \\
\text { Carex tristachya }\end{array}$ \\
\hline $\mathrm{SD}$ & $13.7 \pm 8.6$ & $5-12$ & $\begin{array}{l}\text { Kobresia robusta, } \\
\text { Leymus chinensis, } \\
\text { Potentilla bifurca }\end{array}$ \\
\hline
\end{tabular}

* standard deviation.

egy of space-for-time substitution (Zeng et al., 2013). To assess the degree of degradation of each site, several key vegetation characteristics including total vegetation coverage (VC), dominant species, number of species, aboveground biomass (MA) and below-ground biomass (MB) were determined in mid- to late July 2014. Average field plant height was recorded at $10-15 \mathrm{~cm}$.

For the classification of alpine degradation, various qualitative and semi-qualitative indicators are present in the literature (Gao et al., 2010; Wang et al., 2007; Zeng et al., 2013). In this study, we chose VC, dominant species and number of species as indicators of degradation, and the nine sites were classified into three groups: lightly degraded (LD), moderately degraded (MD), and severely degraded (SD), corresponding to sites 1, 2 and 4, sites 5, 6 and 8, and sites 3, 7 and 9, respectively. Characteristics of the three degradation degrees of alpine meadow are shown in Table 1, and MA and MB of each degree are shown in Fig. 2.

\subsection{Soil sampling and measurements}

Both disturbed and undisturbed soil samples were obtained from 0 to $80 \mathrm{~cm}$ depths at $10 \mathrm{~cm}$ intervals at three points randomly distributed in each investigated site mentioned above. Disturbed samples were collected using a soil auger, and samples of the same layer were thoroughly mixed and then air-dried. After being sieved by 2 and $0.15 \mathrm{~mm}$ mesh, the composite samples were stored in plastic bags and transported to the laboratory for analysis. Soil organic carbon (SOC) was determined by dichromate oxidation with an external heat source (also cited as Walkley-Black wet combustion method; Nelson and Sommers, 1996); 1-2 mm water-stable aggregates (WSAs) were measured using a routine wet-sieve method with the mechanical sieving procedure described by ISSAS (1978). Soil particle composition (sand $>0.05 \mathrm{~mm}$, silt $0.002-0.05 \mathrm{~mm}$, and clay $<0.002 \mathrm{~mm}$ ) was analysed by wet sample dispersion and laser diffrac-

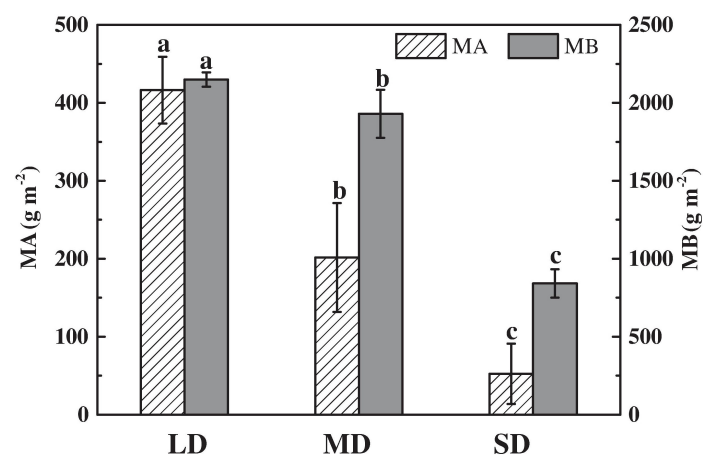

Figure 2. MA and MB of different degradation degrees. The error bars denote the standard deviation of the 3 sites of the same degradation degree. Different letters above the bars denote significant differences $(p<0.05)$ between different degradation degrees. LD: lightly degraded, MD: moderately degraded, SD: severely degraded.

tion method using a laser-scattering particle analyser (Microtrac S3500, Microtrac Inc., USA; Cooper et al., 1984; Zhang et al., 2014).

Undisturbed samples were collected using cylinder cores $(50.46 \mathrm{~mm}$ in diameter and $50 \mathrm{~mm}$ in height) to determine soil physical and hydraulic properties including bulk density (BD), capillary porosity (CP), non-capillary porosity (NCP), field water capacity (FC) and saturated hydraulic conductivity $\left(K_{\mathrm{S}}\right)$. In the laboratory, all these parameters were determined in proper sequence with the water suction method (Fu et al., 2015). First, the cylinder cores were dipped in $5 \mathrm{~mm}$ depth water to absorb water through capillary action for roughly $8 \mathrm{~h}$ before a constant weight was reached; the corresponding weights were recorded as $\mathrm{m} 1$. Second, the cores were soaked in $4.8 \mathrm{~cm}$ depth water for approximately $24 \mathrm{~h}$ until saturated, and the respective weights were recorded as $\mathrm{m} 2$. Third, soil samples were put on dry sand for $48 \mathrm{~h}$ and the resulting weights were recorded as $\mathrm{m} 3$. Subsequently, cylinder cores were linked to a Mariotte's bottle to measure $K_{\mathrm{s}}$ using the constant head method based on Darcy's law (Klute and Dirksen, 1986). Finally, the cores were oven-dried at $105^{\circ} \mathrm{C}$ for approximately $24 \mathrm{~h}$ and the weights were recorded as $\mathrm{m} 4$. No perceivable swelling was detected for all the cores during the soaking process, and the parameters were calculated by the following formulas:

$$
\begin{aligned}
& \mathrm{BD}=\frac{m_{4}}{V}, \\
& \mathrm{CP}=\frac{m_{1}-m_{4}}{V}, \\
& \mathrm{NCP}=\frac{m_{2}-m_{1}}{\rho \cdot V}, \\
& \mathrm{FC}=\frac{m_{3}-m_{4}}{\mathrm{BD} \cdot V},
\end{aligned}
$$


$K_{\mathrm{S}}=\frac{10 \cdot Q \cdot L}{A \cdot \Delta H \cdot t}$,

where $V$ is the volume of the cylinder core $\left(100 \mathrm{~cm}^{3}\right), \rho$ is the water density $\left(1 \mathrm{~g} \mathrm{~cm}^{-3}\right), t$ is the time interval $(10 \mathrm{~min})$, $Q$ is the volume of the outflow through the soil cores during the time interval $t(\mathrm{~mL}), L$ is the length of the soil core $(5 \mathrm{~cm}), \Delta H$ is the height difference of the hydraulic head $(10 \mathrm{~cm})$, and $A$ is the cross-sectional area of the cylinder core $\left(20 \mathrm{~cm}^{2}\right)$.

Above all, soil moisture content (SMC; volumetric) of all investigated sites was measured by time domain reflectometry (TDR) (TRIME-PICO-IPH, TDR, IMKO Inc., Ettlingen, Germany) from 0 to $80 \mathrm{~cm}$ soil depth at $10 \mathrm{~cm}$ intervals from 20 June to 20 July 2014 . The TDR was calibrated in the local alpine region in advance, and the determination accuracy was $\pm 3 \%$. Soil moisture was measured 3 times for each layer of each site. There were no rainfall events recorded within 2 days before the data collection, and each measurement of all sites were finished within 1 day.

\subsection{Statistical analysis}

Data in this study were presented as mean \pm SD (standard deviation). Comparison analysis was performed using SPSS 19.0. A one-way analysis of variance (ANOVA), followed by a least significant difference (LSD) method, was used to test the differences between average values of all parameters at each degradation degree. Pearson correlation coefficient was employed to determine the relationships among vegetation degradation and soil properties.

Redundancy analysis (RDA) was applied to study the relationship between basic soil properties and hydraulic properties by using CANOCO software version 4.5 (Biometris). RDA is a type of constrained ordination method combining multiple regression and principal component analysis (PCA). It aims to represent a multivariate data set (generally a collection of samples with more than two properties) along a reduced number of orthogonal axes, and visualize the data set in a two-dimensional scatter diagram, hence enabling an easier interpretation of the structure of multivariate data and relationships among variables (Borcard et al., 2011). The projections of the arrows onto the axes represent the contribution of corresponding variables to the extracted axes. The cosine of the angle between the arrows reflects the correlation between variables. A Monte Carlo permutation test was used to rank the importance of each explanatory variable, and then the contribution of each variable to the total variance was determined by multiple regression (Leps and Smilauer, 2003).

\section{Results}

\subsection{Variation in basic soil properties and porosity characteristics under different degrees of degradation}

Changes in basic soil properties and porosity characteristics with alpine swamp meadow degradation were obvious (Fig. 3). Statistical analysis showed that SOC and WSAs decreased significantly ( $p<0.05$; Fig. $3 \mathrm{~b}$ and $\mathrm{c})$ and BD increased significantly $(p<0.05$; Fig. $3 \mathrm{a})$ with degradation. Soil texture changed remarkably with degradation; sand content increased significantly $(p<0.05$; Fig. 3f) while significant decreases were observed in silt and clay content $(p<0.05$; Fig. $3 \mathrm{~d}$ and e). The majority of all soil samples were classified as loam and sand (Fig. 4). Half of the LD samples were classified as loam, while the vast majority of MD (17 of 24 samples) and SD (22 of 24 samples) samples were classified as sand. Compared with LD, the SOC, WSAs, and silt and clay content of MD decreased by 17.9, $15.7,5.1$ and $23.1 \%$, respectively, and those of SD decreased by $61.5,32.8,44.0$ and $75.8 \%$, respectively. BD and sand content of MD increased by 2.3 and $2.9 \%$, respectively, and those of SD increased by 7.2 and $19.6 \%$, respectively, when compared with LD.

Soil porosity altered drastically with degradation (Fig. $3 g$ and h). CP decreased consistently with increasing degree of degradation. When compared with $\mathrm{LD}$, mean $\mathrm{CP}$ values of all depths decreased by 5.5 and $13.6 \%$ for MD and SD, respectively. The mean value of NCP decreased from LD to MD by $6.6 \%$ while it increased from MD to SD by $4.4 \%$, following the order of $\mathrm{LD}>\mathrm{SD}>\mathrm{MD}$.

All properties differed most distinctly in surface $(0-10 \mathrm{~cm})$ and subsurface layers $(10-20 \mathrm{~cm})$ among different degradation degrees. The differences gradually diminished with increasing soil depth despite some exceptions (e.g. 40-50 cm for clay and $70-80 \mathrm{~cm}$ for silt). Almost all basic soil properties showed strong depth dependence. For each degradation degree, BD and sand content showed an increasing trend while SOC, WSAs, and silt and clay content decreased consistently with depth from 0 to $80 \mathrm{~cm}$. CP of MD experienced parabolic change with the highest values in the $20-30 \mathrm{~cm}$ layer. NCP was an exception, showing decreases from the $0-40 \mathrm{~cm}$ layer while increasing slightly from the $40-80 \mathrm{~cm}$ layer. For each property, the slope of the vertical variations decreased with degradation.

\subsection{Changes in SMC, FC and $K_{\mathrm{s}}$ with degradation}

SMC in the profile decreased consistently with degradation for all soil layers (Fig. 5). Compared with LD, the mean SMC (0-80 cm layer) of MD and SD decreased by 21.8 and $33.5 \%$, respectively, and SMC declined more from LD to MD than from MD to SD. SMC of different degradation degrees always showed an increasing trend with depth. For MD 

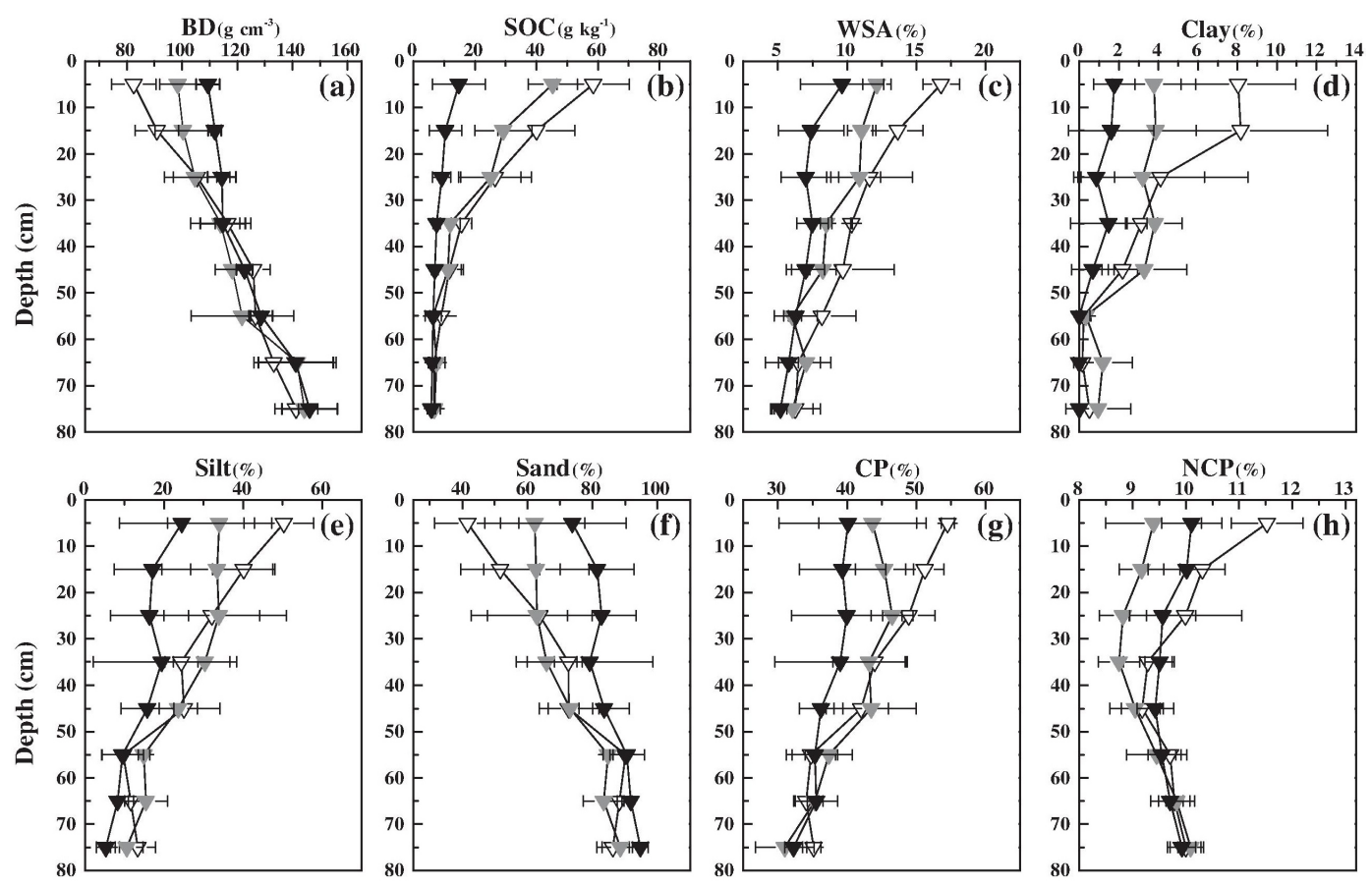

$\rightarrow-\mathrm{LD} \longrightarrow \mathrm{MD} \longrightarrow \mathrm{SD}$

Figure 3. Basic soil properties of different degradation degrees. The error bars denote the standard deviation of the three sites of the same degradation degree. LD: lightly degraded, MD: moderately degraded, SD: severely degraded.

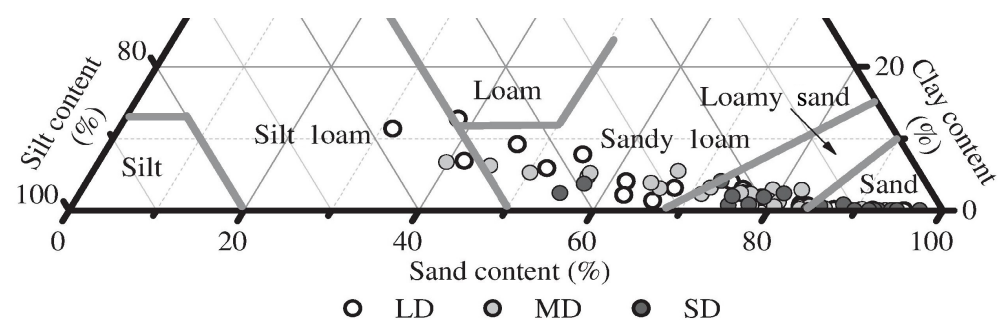

Figure 4. Particle size distributions of lightly degraded (LD), moderately degraded (MD) and severely degraded (SD) soil samples. Textural classes corresponding to particle size distributions observed in these soils are bounded by bold grey lines (e.g. loam, silt).

and SD, SMC increased consistently with depth, while for LD, SMC showed no clear trend in both $0-40$ and $40-80 \mathrm{~cm}$ layers, increasing sharply at $40 \mathrm{~cm}$ depth.

Changes in FC and $K_{\mathrm{S}}$ associated with alpine swamp meadow degradation are displayed in Fig. 6. Both of these properties responded quickly to degradation and showed notable vertical distribution. Mean values of FC decreased consistently with degradation in $0-30 \mathrm{~cm}$ layers but varied irregularly below $30 \mathrm{~cm}$ (Fig. 6a). Unlike FC, $K_{\mathrm{s}}$ decreased from $\mathrm{LD}$ to $\mathrm{MD}$ and then increased from $\mathrm{MD}$ to SD (i.e. $\mathrm{LD}>\mathrm{SD}>\mathrm{MD}$ ) except for layers $40-50$ and 70 $80 \mathrm{~cm}$ (Fig. 6b). It was also evident that $K_{\mathrm{S}}$ values were more variable in the upper soil layers. FC of all degradation degrees decreased consistently with depth, and the slope of the decreasing trend decreased with degradation, while $K_{\mathrm{s}}$ decreased in the $0-40 \mathrm{~cm}$ layers and then increased in the 40
$80 \mathrm{~cm}$ layers, reaching the lowest values at $40 \mathrm{~cm}$. Similar patterns of change and vertical distribution were observed for NCP (see Sect. 3.1).

ANOVA showed that SMC of LD was significantly higher $(p<0.05)$ than that of MD in all soil layers except for the $20-30 \mathrm{~cm}$ layer, and SMC of MD was significantly higher than that of SD in the $10-80 \mathrm{~cm}$ layers. In contrast to SMC, significant differences among the three degrees of degradation only existed in the $0-20 \mathrm{~cm}$ layers for FC, and the 0 $10 \mathrm{~cm}$ layer for $K_{\mathrm{s}}$. These statistical analyses indicated that alpine meadow degradation did not have significant impacts on soil hydraulic properties in layers deeper than $20 \mathrm{~cm}$. 
Table 2. Pearson correlation coefficients between vegetation characteristics and soil properties in 0-40 and 40-80 cm layers.

\begin{tabular}{llllllllll}
\hline Layers & Properties & BD & SOC & WSA & Sand & Silt & Clay & CP & NCP \\
\hline $0-40 \mathrm{~cm}$ & VC & $-0.710^{* *}$ & $0.769^{* *}$ & $0.747^{* *}$ & $0.533^{*}$ & $0.472^{*}$ & $-0.491^{*}$ & $0.829^{* *}$ & 0.155 \\
& MA & $-0.811^{* *}$ & $0.899^{* *}$ & $0.902^{* *}$ & $0.838^{* *}$ & $0.698^{* *}$ & $-0.735^{* *}$ & $0.808^{* *}$ & 0.345 \\
& MB & $-0.635^{* *}$ & $0.860^{* *}$ & $0.800^{* *}$ & $0.672^{* *}$ & $0.646^{* *}$ & $-0.662^{* *}$ & $0.615^{* *}$ & 0.028 \\
\hline \multirow{2}{*}{$40-80 \mathrm{~cm}$} & VC & -0.187 & $0.658^{* *}$ & $0.586^{* *}$ & 0.249 & 0.420 & -0.405 & 0.321 & -0.407 \\
& MB & $-0.487^{*}$ & $0.461^{*}$ & $0.464^{*}$ & 0.365 & $0.507^{*}$ & $-0.502^{*}$ & $0.544^{*}$ & -0.030 \\
& MA & -0.352 & $0.474^{*}$ & $0.461^{*}$ & 0.369 & $0.694^{* *}$ & $-0.661^{* *}$ & 0.412 & 0.010 \\
\hline
\end{tabular}

* significant at 0.05 level. ${ }^{* *}$, significant at 0.01 level (two-tailed test); $n=18$.

Table 3. Pearson correlation coefficients between $K_{\mathrm{S}}$, FC and soil properties of soil in layers above $20 \mathrm{~cm}$ depth.

\begin{tabular}{lllllllll}
\hline Properties & BD & SOC & WSA & Sand & Silt & Clay & CP & NCP \\
\hline$K_{\mathrm{S}}$ & -0.447 & -0.239 & -0.246 & -0.381 & 0.366 & 0.391 & 0.172 & $0.896^{*}$ \\
FC & $-0.912^{*}$ & $0.867^{*}$ & $0.875^{*}$ & $-0.803^{*}$ & $0.786^{*}$ & $0.760^{*}$ & $0.918^{*}$ & 0.361 \\
\hline
\end{tabular}

* significant at 0.01 level (two-tailed test); $n=18$.

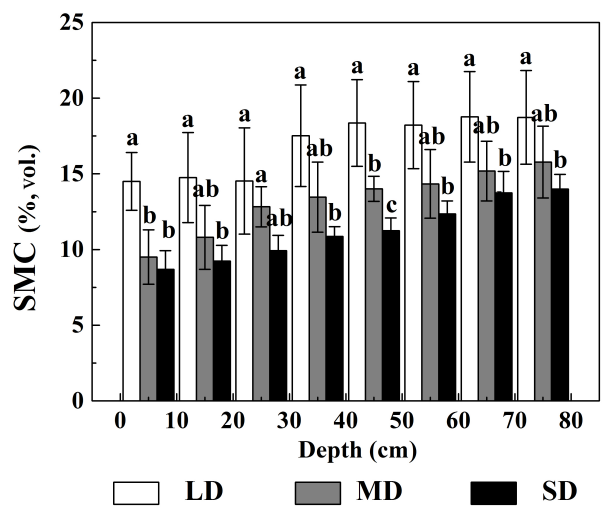

Figure 5. Soil moisture content (SMC) of different degradation degrees. Error bars denote the standard deviation of the three sites of the same degradation degree. Bars with the same letter indicate that no significant differences $(p<0.05)$ exist between corresponding degradation degrees. LD: lightly degraded, MD: moderately degraded, SD: severely degraded.

\subsection{Influencing factors of degradation on soil hydraulic properties}

Alpine swamp meadow degradation directly leads to deterioration of basic soil properties, and thus soil hydraulic properties are influenced. Pearson correlation analysis (Table 2) showed the effects of vegetation characteristics on soil properties. Generally, SOC, WSAs, CP and clay and silt content were positively correlated with $\mathrm{VC}, \mathrm{MA}$ and $\mathrm{MB}$, while $\mathrm{BD}$ and sand content were negatively correlated with vegetation characteristics. The correlation between NCP and vegetation characteristics was not significant because of its inconsistent change pattern with degradation. Compared with those in the
$40-80 \mathrm{~cm}$ layers, soil properties in the $0-40 \mathrm{~cm}$ layers were all significantly ( $p<0.05$ or 0.01$)$ correlated with vegetation characteristics, indicating that the effects of vegetation degradation on soil properties were mostly confined to the upper soil layers.

According to the statistical analysis in Sect. 3.2, data of samples in the $0-10$ and $10-20 \mathrm{~cm}$ layers were selected to analyse the relationships between basic soil properties and hydraulic properties associated with degradation. Figure 7 illustrates the relationships between soil basic and hydraulic properties ascertained by the RDA. FC was positively correlated with CP, WSAs, SOC, and silt and clay content, but was negatively correlated with BD and sand content. NCP had no impact on FC, but served as the only factor that determined $K_{\mathrm{S}}$. FC and $K_{\mathrm{S}}$ are independent of each other, which can be further supported by Pearson correlation analysis (Table 3 ). The two axes explained 60.2 and $29.0 \%$ of the total variance in FC and $K_{\mathrm{s}}$, respectively.

Additionally, all the samples could be divided into two groups: one included all the samples from LD and two samples from SD, while the other included all the samples from MD and four samples from SD. The group including LD samples showed a close relationship with all the soil properties except BD and sand, while the second group, mainly including MD and SD, showed the opposite.

Soil basic properties were treated as explanatory variables to explain the total variance of $K_{\mathrm{S}}$ and FC. A Monte Carlo permutation test was first used to rank the importance of each explanatory variable, and then the relative contributions of each variable to the total variance of $K_{\mathrm{S}}$ and FC were determined by multiple regression. The results showed (Table 4) that $\mathrm{CP}$ was the dominant factor for FC, explaining $91.9 \%$ of the variance in FC. NCP was the dominant factor for $K_{\mathrm{S}}$, explaining $97.0 \%$ of the variance in $K_{\mathrm{s}}$. As these properties 

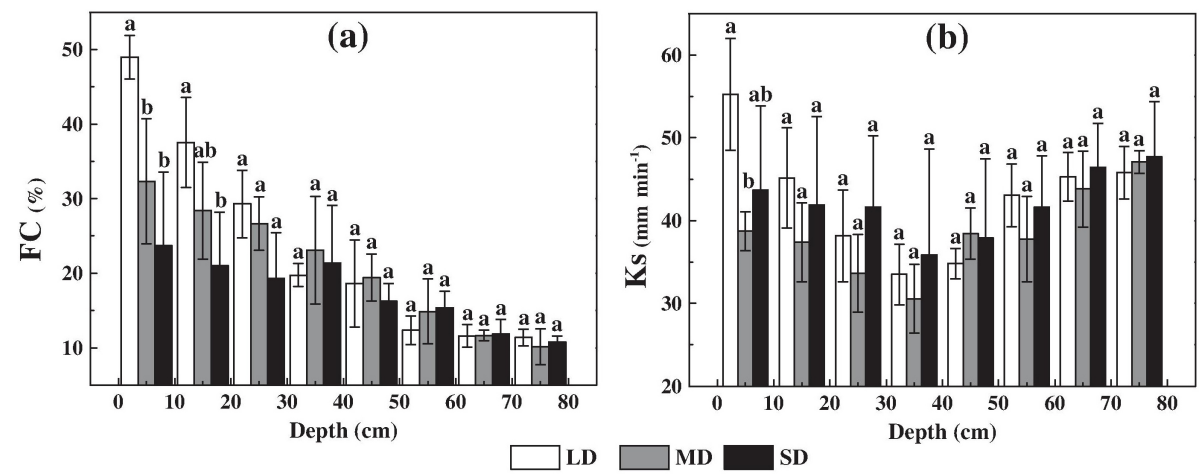

Figure 6. Differences in field capacity $(\mathrm{FC})$ and saturated hydraulic conductivity $\left(K_{\mathrm{S}}\right)$ with degradation degree. Error bars denote the standard deviation of the three sites of the same degradation degree. Bars with the same letter indicate that no significant differences $(p<0.05)$ exist between corresponding degradation degrees. LD: lightly degraded, MD: moderately degraded, SD: severely degraded.

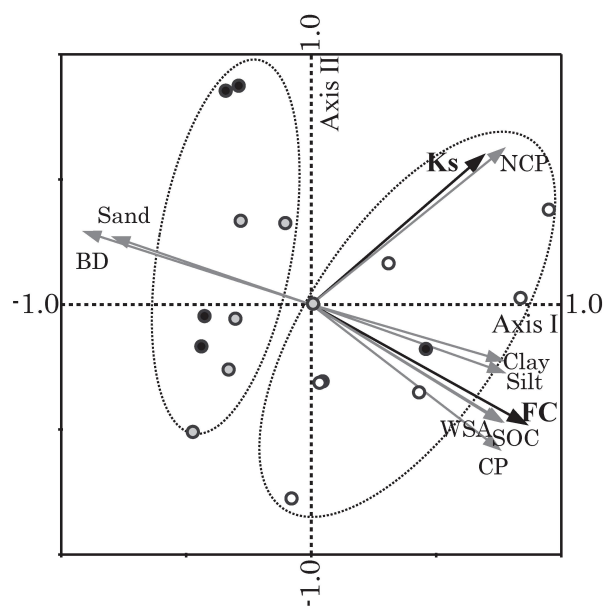

Figure 7. Redundancy analysis of soil hydraulic properties and basic properties under different degradation stages. Symbols " $\bigcirc$ ", gray and black "•" denote soil samples from lightly degraded (LD), moderately degraded (MD) and severely degraded (SD), respectively. The two axes represent the principal component (PC) extracted from the explanatory variables (basic soil properties). The first ordination axis (axis I, horizontal) mainly reflected the influence of bulk density (BD), soil organic carbon (SOC) and soil texture, and the second axis (axis II, vertical) mainly reflected the influence of capillary porosity $(\mathrm{CP})$ and non-capillary porosity (NCP). FC: field capacity, $K_{\mathrm{s}}$ : saturated hydraulic conductivity, WSAs: water-stable aggregates.

explain large proportions of the variance in $\mathrm{FC}$ and $K_{\mathrm{S}}$, the relative influence of other soil properties can be dismissed.

\section{Discussion}

\subsection{Effects of alpine swamp meadow degradation on SMC and basic soil properties}

SMC is a comprehensive indicator of soil quality and can directly reflect soil water holding capacity (Palese et al., 2014; Zeng et al., 2013). This study showed that SMC decreased consistently from LD to SD, responding swiftly to degradation. Unlike soil properties, significant differences in SMC among the three degradation degrees were found at all soil layers. Similar changing patterns with vegetation degradation in alpine regions were observed by Zeng et al. (2013), Wang et al. (2007) and Li et al. (2012). In fact, decreases in vegetation coverage and SOC and increases in sand content will negatively impact on soil water retention (Strudley et al., 2008; Yi et al., 2012), leading to loss of SMC with degradation. Moreover, because of the intensified root uptake and soil evaporation in summer, SMC of all degradation degrees in the $0-30 \mathrm{~cm}$ layers were lower than those in deeper layers.

Changes in basic soil properties, such as increases in BD and sand content and decreases in SOC, WSAs, and silt and clay content with degradation (Fig. 2a-f) align closely with the hypothesized results and are in agreement with much of the literature (Gao et al., 2010; Wang et al., 2007; Wei et al., 2010; Zeng et al., 2013). Along the degradation gradient, trends in these basic properties are almost uniform regardless of soil types and vegetation traits (Guo and Shao, 2013; Zeng et al., 2013). On the contrary, basic soil properties will improve consistently during restoration processes (Li and Shao, 2006; Wu et al., 2010). Moreover, changes in basic soil properties with degradation were mostly confined to the upper layers $(0-40 \mathrm{~cm})$, and the contrasts were most remarkable in the surface layer $(0-10 \mathrm{~cm})$. Similar change patterns with soil depth have also been confirmed in many other studies (Fu et al., 2015; Hallema et al., 2015; Wang et al., 2007; Zeng et al., 2013). Correlation analysis showed that soil properties, especially in the upper layers $(0-40 \mathrm{~cm})$, 
Table 4. Total variance of FC and $K_{\mathrm{S}}$ explained by basic soil properties.

\begin{tabular}{|c|c|c|c|c|c|c|}
\hline \multirow[t]{2}{*}{ Ranking } & \multicolumn{3}{|c|}{$\mathrm{FC}$} & \multicolumn{3}{|c|}{$K_{\mathrm{s}}$} \\
\hline & Properties & $\begin{array}{r}\% \text { of } \\
\text { variance }\end{array}$ & $\begin{array}{r}\text { Cumulative } \\
\%\end{array}$ & Properties & $\begin{array}{r}\% \text { of } \\
\text { variance }\end{array}$ & $\begin{array}{r}\text { Cumulative } \\
\%\end{array}$ \\
\hline 1 & $\mathrm{CP}$ & 91.1 & 91.1 & $\mathrm{NCP}$ & 97.3 & 97.3 \\
\hline 2 & WSA & 7.5 & 98.6 & $\mathrm{BD}$ & 1.8 & 99.1 \\
\hline 3 & $\mathrm{NCP}$ & 0.7 & 99.3 & WSA & 0.5 & 99.6 \\
\hline 4 & Silt & 0.5 & 99.8 & $\mathrm{CP}$ & 0.2 & 99.8 \\
\hline 5 & $\mathrm{BD}$ & 0.2 & 100.0 & Clay & 0.1 & 99.9 \\
\hline 6 & SOC & 0.0 & 100.0 & Silt & 0.1 & 100.0 \\
\hline 7 & Clay & 0.0 & 100.0 & Sand & 0.0 & 100.0 \\
\hline 8 & Sand & 0.0 & 100.0 & SOC & 0.0 & 100.0 \\
\hline
\end{tabular}

were closely associated with vegetation characteristics (Table 2). Vegetation factors are indispensable to the stability of soil status, such as the formation of SOC, porosity and structure. In fact, root activity and litter fall input decrease significantly or disappear as degradation degree increases, and thus the decomposition process and organic matter accumulation in soil are hindered with degradation. Depletion of SOC greatly alters the soil micro-environment and might trigger a series of changes in soil physical, chemical and biological processes (Nelson and Sommers, 1996). For instance, it has been confirmed that clay and silt contents are largely dependent on the release of organic acid from soil organic matter, which can corrode coarse minerals and transfer large grains into fine particles (Fan et al., 2015). Organic matter can also act as "glue" in soil aggregate formation and determine water stability (Lipiec et al., 2009). Therefore, a decrease in SOC will strongly influence soil structure, and thus brings about overall changes in soil physical and chemical properties. Furthermore, the absence of plant coverage and root grasp will cause topsoil to become vulnerable to wind, raindrops, surface flow and compaction, directly resulting in soil erosion and degradation, and the particle distribution of soil samples in the soil texture triangle (Fig. 4) clearly shows the sandification trend with increasing degradation. Insignificant correlations between vegetation characteristics and soil properties of the deep layers $(40-80 \mathrm{~cm}$; Table 2$)$ were in accordance with the fact that no significant differences in soil basic properties were found among degradation degrees in the deep layers.

\subsection{Influencing factors of alpine swamp meadow degradation on soil hydraulic properties}

With increasing degradation degree, our results demonstrated that FC decreased consistently (Fig. 6a), which was in accordance with some previous studies conducted in other alpine ecosystem types (Xiong et al., 2011; Yi et al., 2012). However, other studies reported different change patterns of FC. Li et al. (2012) and Wei et al. (2010) found that FC first increased but then decreased with alpine meadow degradation.
This might be caused by different degradation classification. Li et al. (2012) and Wei et al. (2010) classified the sampling plots into four and five degradation degrees according to succession stages, respectively, and the initial degree of the sampling plots in both studies was non-degraded. However, the highest values of FC in both studies corresponded to the light degree, and FC of the most severely degraded sites were much lower than those of non-degraded sites. These traits were in line with our results. Wei et al. (2010) noted that CP changed similarly with degradation, i.e. CP was positively correlated with FC, which was consistent with the definition of FC (Ottoni Filho et al., 2014).

$K_{\mathrm{S}}$ decreased initially and then increased with degradation (Fig. 6b), and similar "high-low-high" trends in $K_{\mathrm{S}}$ were also observed in some studies conducted for alpine meadow, although the amplitude of change was different (Wang et al., 2010; Wei et al., 2010). However, Zeng et al. (2013) reported a decreasing trend while Wang et al. (2007) reported an increasing trend of $K_{\mathrm{s}}$. These discrepancies might be attributed to the difference in soil and vegetation factors in different regions and also the degradation classification. In the study conducted by Zeng et al. (2013), the root density consistently decreased by an average of $97 \%$ from light to extreme degree, which indicated a substantial decrease in soil macropores and thus resulted in lower values of $K_{\mathrm{s}}$; in the study conducted by Wang et al. (2007), the gravel (size $>2 \mathrm{~mm}$ ) content increased by nearly 100 -fold, which will greatly increase soil infiltration.

Soil pores are empty space active in soil water storage, retention and movement; therefore soil porosity is closely related to soil hydraulic properties (Lipiec et al., 2006). Increases in $\mathrm{BD}$ indicate a reduction in soil total porosity (TP) since TP is generally calculated using the following equation: $\mathrm{TP}=1-\mathrm{BD} / 2.65$ (Li and Shao, 2006; Price et al., 2010). TP can be divided into CP (pore size $<0.1 \mathrm{~mm}$ ) and NCP (pore size $>0.1 \mathrm{~mm}$ ). Water that fills capillary pores can be suspended by the capillary effect, making CP vital for soil water retention. However, in non-capillary pores, soil water can move freely by gravity making NCP critical for soil wa- 
ter infiltration and transmission. Generally, soil pores with pore size larger than $75 \mu \mathrm{m}$ are defined as macro-pores, and non-capillary pores belong to the category of macro-pores (Gao et al., 2015; Pagliai and Vignozzi, 2002). Soil porosity mainly depends on soil texture and aggregates (i.e. the finer the texture of the soil, the smaller the pore size). Applying this logic, increasing degradation would increase sand content and decrease WSAs, and thus lead to a decrease in CP (Fu et al., 2015; Lipiec et al., 2006). Moreover, a positive correlation between $\mathrm{CP}$ and SOC was detected in many studies (Gao et al., 2015; Price et al., 2010; Yu et al., 2015), reflecting that $\mathrm{CP}$ can be an indicator of soil quality. By definition, $\mathrm{FC}$ is the maximum water content held in soils when excess water has drained away and the downward flux is negligible (Ottoni Filho et al., 2014). Therefore, FC is essentially dependent on the capillary effect; decreased FC is the result of a decrease in $\mathrm{CP}$.

Unlike CP, changes in NCP in this study were more complex; NCP first decreased from LD to MD and then increased from MD to $\mathrm{SD}$ (i.e. $\mathrm{MD}<\mathrm{SD}<\mathrm{LD}$; Fig. $3 \mathrm{~h}$ ). It is widely accepted that soil macropores are closely related to root penetration and activities of soil fauna (Kuncoro et al., 2014; Zeng et al., 2013). NCP measured in the rhizosphere $(0-20 \mathrm{~cm}$ layer) decreased significantly as root penetration weakened with degradation. In contrast, increases in sand content will lead to an increase in the size of soil pores. Hence, the slight but observed increase in NCP from MD to $\mathrm{SD}$. However, the effect is not equivalent with root penetration resulting in macro-pores, i.e. the contribution of increasing sand content to NCP could not offset the diminishing effects of vegetation on soil porosity, and hence NCP of SD was higher than that of MD but still lower than that of LD. $K_{\mathrm{S}}$ determines soil water movement and is largely dominated by NCP (Tables 3 and 4), so NCP changed in accordance with $K_{\mathrm{s}}$.

In summary, our study revealed that the well-identified relationships between soil porosity and hydraulic properties are applicable in alpine swamp meadow. Hence, compared with soil porosity, the contributions of other properties to the variance of FC and $K_{\mathrm{S}}$ were outweighed (Table 4). In addition, FC was positively correlated with SOC, WSAs, and silt and clay content $(p<0.05)$, and negatively correlated with $\mathrm{BD}$ and sand content $(p<0.05$; Table 3$)$; these correlations were consistent with studies in other regions (Głąb and Szewczyk, 2014; Price et al., 2010; Wei et al., 2010). Because of the inconsistent changing pattern, $K_{\mathrm{s}}$ only positively correlated with NCP (Table 3). In fact, arguments about the impact of soil properties on $K_{\mathrm{S}}$ and its changes are still under debate (Fu et al., 2015; Jarvis et al., 2013). Hence, further investigations about variations of $K_{\mathrm{s}}$ are needed.

\subsection{Implications and uncertainties of this study}

Our results show a clear distinction between basic soil and hydraulic properties among different alpine meadow degra- dation degrees. Considering the important roles that FC and $K_{\mathrm{S}}$ play in soil water retention and infiltration, it can be concluded that key hydraulic processes and functions in soil such as water holding capacity, transmission and runoff generation mechanisms might differ significantly with alpine swamp meadow degradation. For example, high $K_{\mathrm{S}}$ seen in topsoil can form preferential flow and avoid infiltration excess runoff (Fu et al., 2015; Lipiec et al., 2006). In this study, soils of LD had relatively high $K_{\mathrm{S}}$ and FC, indicating the robustness of soil water retention. For MD, $K_{\mathrm{S}}$ values were reduced significantly; low $K_{\mathrm{S}}$ might act as a barrier to vertical water flow, reducing its capacity to intercept rainfall.

Furthermore, the results showed that the effects of degradation mainly manifest in the upper soil layers. There are only a few influences of degradation in deep soil layers. Moreover, the rhizosphere lies at the interface between the atmosphere and the ground surface and directly accepts precipitation, recharges deep soil layers and supplies water to plant growth (Li et al., 2012; Wu et al., 2014). In this sense, the rhizosphere is of great hydrological importance to alpine ecosystems, and changes in soil hydraulic properties of this layer could greatly alter the soil hydraulic processes in local regions.

The hydrological effects of large-scale alpine meadow degradation are noticeable and serious in the Tibetan Plateau (Jin et al., 2015; Wang et al., 2012). For hydrological modelling, accurate parameter acquisition is necessary for simulation accuracy (Vereecken et al., 2015). Our results indicate that hydraulic properties will be altered significantly both vertically and spatially with degradation. Therefore, to improve the performance of hydrological modelling, differences in soil hydraulic properties under different degradation degrees should be seriously considered (Jin et al., 2015).

Despite the fact that this study revealed the effect of alpine meadow degradation on soil hydraulic properties, some uncertainties still exist. First, it should be noted that degradation is a non-linear and consecutive process while in practice people have to divide it into a limited number of degrees according to some criteria. In Sect. 3.2, we have pointed out that the change patterns of FC varied with degradation classification, and actually our classification was relatively rough. Therefore, to obtain robust conclusions about alpine grassland degradation on soil hydraulic properties, more alpine grassland plots should be established and more degradation degrees should be classified in future investigations. Terrestrial ecosystem degradation is essentially a positive feedback loop composed of vegetation retrogressive succession and soil deterioration (King and Hobbs, 2006). Thus, understanding the effect of vegetation degradation on soil hydraulic properties is somewhat insufficient; thereby the interactions between vegetation and soil hydrology should be addressed in further studies. 


\section{Conclusions}

Because of global change and anthropogenic disturbances, alpine swamp meadow on the eastern Tibetan Plateau is undergoing severe degradation. Based on nine plots representing alpine swamp meadow of different degradation degrees, this study mainly investigated the changes in soil hydraulic properties with alpine swamp meadow degradation, and analysed the influencing mechanism of grassland degradation on FC and saturated hydraulic conductivity $\left(K_{\mathrm{S}}\right)$. In summary, with increasing degradation degree, SMC and FC decreased consistently from LD to SD, while $K_{\mathrm{S}}$ decreased from $\mathrm{LD}$ to $\mathrm{MD}$ and then increased from $\mathrm{MD}$ to $\mathrm{SD}$ (i.e. $\mathrm{LD}>\mathrm{SD}>\mathrm{MD}$ ). BD, SOC, WSAs, soil texture and porosity were also substantially altered. Significant differences in both soil basic and hydraulic properties between different degradation degrees usually exist in the $0-20 \mathrm{~cm}$ layer, indicating that the effect of degradation was mostly concentrated in the upper soil layers and the rhizosphere. FC was positively correlated with CP, WSAs, SOC, and silt and clay content, but was negatively correlated with $\mathrm{BD}$ and sand content; $K_{\mathrm{S}}$ was only positively correlated with NCP.

Changes in FC and $K_{\mathrm{S}}$ are mainly controlled by soil porosity during the degradation process. $\mathrm{CP}$ and NCP are dominant factors, which explained 91.1 and $97.3 \%$ of the variance of FC and $K_{\mathrm{s}}$, respectively. Root activities attenuate with degradation and directly lead to a decrease in NCP, while the contribution of sand particles to NCP is important for MD and $\mathrm{SD}$ when vegetation diminishes or disappears. The combined effect of disappearing root activities and increased sand content is responsible for the inconsistent changes in NCP and $K_{\mathrm{S}}$ during the degradation processes. Our findings provide a more comprehensive understanding of the soil hydrological effects of vegetation degradation. Given the importance of parameterization for hydrological models, water flow simulations in the Tibetan Plateau and similar regions should consider variations in soil hydraulic properties of different degraded alpine swamp meadow.

Data availability. All data used in this paper are available on request from the corresponding authors.

Competing interests. The authors declare that they have no conflict of interest.

Acknowledgements. This study was supported by the National Natural Science Foundation of China (41671107 and 41301092) and the Youth Innovation Promotion Association of the Chinese Academy of Sciences (2016049). We thank Zhang Yu, Wang Shaoying and Zhao Wanglong for their help with field work. We are also in debt to Gao Xiaofei for his assistance in soil treatment and analysis. In addition, we appreciate the anonymous reviewers' valuable suggestions to improve the paper.
Edited by: L. Wang

Reviewed by: two anonymous referees

\section{References}

Bai, J. H., Lu, Q. Q., Wang, J. J., Zhao, Q. Q., Ouyang, H., Deng,W., and Li, A. N.: Landscape pattern evolution processes of alpine wetlands and their driving factors in the Zoige Plateau of China, J. Mount. Sci., 10, 54-67, doi:10.1007/s11629-013-2572$1,2013$.

Bernhardt, M., Harer, S., Jacobeit, J., Wetzel, E. F., and Schulz, K.: The Virtual Alpine Observatory - research focus Alpine hydrology, Hydrol. Wasserbewirt., 58, 241-243, 2014.

Boluwade, A. and Madramootoo, C.: Modelling the Impacts of Spatial Heterogeneity in the Castor Watershed on Runoff, Sediment, and Phosphorus Loss Using SWAT: I. Impacts of Spatial Variability of Soil Properties, Water Air Soil Poll., 224, 1692, doi:10.1007/s11270-013-1692-0, 2013.

Borcard, D., Gillet, F., and Legendre, H. P.: Numerical Ecology with R, Springer, New York, doi:10.1007/978-1-4419-7976-6, 2011.

Cassel, D. K. and Nielsen, D. R.:Field Capacity and Available Water Capacity, in: Methods of Soil Analysis: Part 1 - Physical and Mineralogical Methods, edited by: Klute, A., Soil Science Society of America, American Society of Agronomy, Madison, WI, 901-926, 1986.

Cooper, L. R., Haverland, R. L., Hendricks, D. M., and Knisel, W. G.: Microtrac Particle-size Analyzer-an alternative particle-size determination method for sediment and soils, Soil Sci., 138, 138146, doi:10.1097/00010694-198408000-00007, 1984.

Fan, T. T., Wang, Y. J., Li, C. B., Zhou, D. M., and Friedman, S. P.: Effects of Soil Organic Matter on Sorption of Metal Ions on Soil Clay Particles, Soil Sci. Soc. Am. J., 79, 794-802, doi:10.2136/sssaj2014.06.0245, 2015.

Fu, T. G., Chen, H. S., Zhang, W., Nie, Y. P., and Wang, K. L.: Vertical distribution of soil saturated hydraulic conductivity and its influencing factors in a small karst catchment in Southwest China, Environ. Monit. Assess., 187, 92, doi:10.1007/s10661015-4320-1, 2015.

Gao, Q. Z., Wan, Y. F., Xu, H. M., Li, Y., Jiangcun, W. Z., and Borjigidai, A.: Alpine grassland degradation index and its response to recent climate variability in Northern Tibet, China, Quatern. Int., 226, 143-150, doi:10.1016/j.quaint.2009.10.035, 2010.

Gao, R., Shi, J., Huang, R., Wang, Z., and Luo, Y. Q.: Effects of pine wilt disease invasion on soil properties and Masson pine forest communities in the Three Gorges reservoir region, China, Ecol. Evol., 5, 1702-1716, doi:10.1002/ece3.1326, 2015.

Ghimire, C. P,, Bruijnzeel, L. A., Bonell, M., Coles, N., Lubczynski, M. W., and Gilmour, D. A.: The effects of sustained forest use on hillslope soil hydraulic conductivity in the Middle Mountains of Central Nepal, Ecohydrology, 7, 478-495, doi:10.1002/eco.1367, 2014.

Głąb, T. and Szewczyk, W: Influence of simulated traffic and roots of turfgrass species on soil pore characteristics, Geoderma, 230 231, 221-228, doi:10.1016/j.geoderma.2014.04.015, 2014.

Guo, Z. and Shao, M. A.: Impact of afforestation density on soil and water conservation of the semiarid Loess Plateau, China, J. Soil Water Conserv., 68, 401-410, doi:10.2489/jswc.68.5.401, 2013. 
Hallema, D. W., Lafond, J. A., Periard, Y., Gumiere, S. J., Sun, G., and Caron, J.: Long-Term Effects of Peatland Cultivation on Soil Physical and Hydraulic Properties: Case Study in Canada, Vadose Zone J., 14, 6, doi:10.2136/vzj2014.10.0147, 2015.

Hu, G. Y., Dong, Z. B., Lu, J. F., and Yan, C. Z.: The developmental trend and influencing factors of aeolian desertification in the Zoige Basin, eastern Qinghai-Tibet Plateau, Aeolian Res., 19, 275-281, doi:10.1016/j.aeolia.2015.02.002, 2015.

Huo, L. L., Chen, Z. K., Zou, Y. C., Lu, X. G., Zou, J. W., and Tang, X. G.: Effect of Zoige alpine wetland degradation on the density and fractions of soil organic carbon, Ecol. Eng., 51, 287-295, doi:10.1016/j.ecoleng.2012.12.020, 2013.

ISSAS: Soil Physical and Chemical Analysis, Shanghai Science and Technology Press, Shanghai, 515-517, 1978.

Jarvis, N., Koestel, J., Messing, I., Moeys, J., and Lindahl, A.: Influence of soil, land use and climatic factors on the hydraulic conductivity of soil, Hydrol. Earth Syst. Sci., 17, 5185-5195, doi:10.5194/hess-17-5185-2013, 2013.

Jin, X., Zhang, L., Gu, J., Zhao, L., Tian, J., and He, C. S.: Modelling the impacts of spatial heterogeneity in soil hydraulic properties on hydrological process in the upper reach of the Heihe River in the Qilian Mountains, Northwest China, Hydrol. Process., 29, 3318-3327, doi:10.1002/hyp.10437, 2015.

King, E. G. and Hobbs, R. J.: Identifying linkages among conceptual models of ecosystem degradation and restoration: Towards an integrative framework, Restor. Ecol., 14, 369-378, doi:10.1111/j.1526-100X.2006.00145.x, 2006.

Klute, A. and Dirksen, C.: Hydraulic Conductivity and Diffusivity: Laboratory Methods, in: Methods of Soil Analysis: Part 1 - Physical and Mineralogical Methods, edited by: Klute, A., Soil Science Society of America, American Society of Agronomy, Madison, WI, 687-734, 1986.

Kormann, C., Francke, T., and Bronstert, A.: Detection of regional climate change effects on alpine hydrology by daily resolution trend analysis in Tyrol, Austria, J. Water Clim. Change, 6, 124143, doi:10.2166/wcc.2014.099, 2015.

Krummelbein, J., Peth, S., Zhao, Y., and Horn, R.: Grazing-induced alterations of soil hydraulic properties and functions in Inner Mongolia, PR China, J. Plant Nutr. Soil Sci., 172, 769-776, doi:10.1002/jpln.200800218, 2009.

Kuncoro, P. H., Koga, K., Satta, N., and Muto, Y.: A study on the effect of compaction on transport properties of soil gas and water. II: Soil pore structure indices, Soil Till. Res., 143, 180-187, doi:10.1016/j.still.2014.01.008, 2014.

Laghari, A. N., Vanham, D., and Rauch, W.: To what extent does climate change result in a shift in Alpine hydrology? A case study in the Austrian Alps, Hydrolog. Sci. J., 57, 103-117, doi:10.1080/02626667.2011.637040, 2012.

Lal, R.: Deforestation and land-use effects on soil degradation and rehabilitation in western Nigeria. 1. Soil physical and hydrological properties, Land Degrad. Dev., 7, 19-45, 1996.

Legates, D. R., Mahmood, R., Levia, D. F., DeLiberty, T. L., Quiring, S. M., Houser, C., and Nelson, F. E. : Soil moisture: A central and unifying theme in physical geography, Prog. Phys. Geogr., 35, 65-86, doi:10.1177/0309133310386514, 2011.

Leij, F. J., Romano, N., Palladino, M., Schaap, M. G., and Coppola, A.: Topographical attributes to predict soil hydraulic properties along a hillslope transect, Water Resour. Res., 40, W02407, doi:10.1029/2002WR001641, 2004.
Leitinger, G., Tasser, E., Newesely, C., Obojes, N., and Tappeiner, U.: Seasonal dynamics of surface runoff in mountain grassland ecosystems differing in land use, J. Hydrol., 385, 95-104, doi:10.1016/j.jhydrol.2010.02.006, 2010.

Leps, J. and Smilauer, P.: Multivariate analysis of ecological data using CANOCO, Cambridge University Press, Cambridge, 2003.

Li, J., Du, Y. G., Zhang, F. W., Guo, X. W., Han, D. R., Liu, S. L., and Cao, G. M.: Mattic Epipedon Impact on Water Conservation in Alpine Meadow, Acta Agrest. Sin., 20, 836-841, 2012.

Li, Y. Y. and Shao, M. A.: Change of soil physical properties under long-term natural vegetation restoration in the Loess Plateau of China, J. Arid Environ., 64, 77-96, doi:10.1016/j.jaridenv.2005.04.005, 2006.

Lipiec, J., Kus, J., Slowinska-Jurkiewicz, A., and Nosalewicz, A.: Soil porosity and water infiltration as influenced by tillage methods, Soil Till. Res., 89, 210-220, doi:10.1016/j.still.2005.07.012, 2006.

Lipiec, J., Wojciga, A., and Horn, R.: Hydraulic properties of soil aggregates as influenced by compaction, Soil Till. Res., 103, 170-177, doi:10.1016/j.still.2008.10.021, 2009.

Ma, L. W., Ahuja, L. R., Trout, T. J., Nolan, B. T., and Malone, R. W.: Simulating Maize Yield and Biomass with Spatial Variability of Soil Field Capacity, Agron. J., 108, 171-184, doi:10.2134/agronj2015.0206, 2016.

Marshall, M. R., Ballard, C. E., Frogbrook, Z. L., Solloway, I., McIntyre, N., Reynolds, B., and Wheater, H. S.: The impact of rural land management changes on soil hydraulic properties and runoff processes: results from experimental plots in upland UK, Hydrol. Process., 28, 2617-2629, doi:10.1002/hyp.9826, 2014.

Mubarak, I., Mailhol, J. C., Angulo-Jaramillo, R., Ruelle, P., Boivin, P., and Khaledian, M.: Temporal variability in soil hydraulic properties under drip irrigation, Geoderma, 150, 158165, doi:10.1016/j.geoderma.2009.01.022, 2009.

Nelson, D. W. and Sommers, L. E.: Total carbon, organic carbon, and organic matter, in: Methods of Soil Analysis. Part 3 - Chemical Methods, edited by: Sparks, D. L., Page, A. L., Sumner, M. E., Tabatabai, A., Helmke, P. A., Loeppert, R. H., Soltanpour, R. N., and Johnson, C. T., Soil Science Society of America Inc., Madison, WI, USA, 961-1010, 1996.

Niemeyer, R. J., Fremier, A. K., Heinse, R., Chavez, W., and DeClerck, F. A. J.: Woody Vegetation Increases Saturated Hydraulic Conductivity in Dry Tropical Nicaragua, Vadose Zone J., 13, doi:10.2136/vzj2013.01.0025, 2014.

Ottoni Filho, T. B., Ottoni, M. V., de Oliveira, M. B., de Macedo, J. R., and Reichardt, K.: Revisiting Field Capacity (FC): Variation of Definition of FC and its Estimation from Pedotransfer Functions, Revista Brasileira De Ciencia Do Solo, 38, 1750-1764, 2014.

Pachepsky, Y. and Park, Y.: Saturated Hydraulic Conductivity of US Soils Grouped According to Textural Class and Bulk Density, Soil Sci. Soc. Am. J., 79, 1094-1100, doi:10.2136/sssaj2015.02.0067, 2015.

Pagliai, M. and Vignozzi, N.: The soil pore system as an indicator of soil quality, Adv. Geoecol., 35, 71-82, 2002.

Palese, A. M., Vignozzi, N., Celano, G., Agnelli, A. E., Pagliai, M., and Xiloyannis, C.: Influence of soil management on soil physical characteristics and water storage in a mature rainfed olive orchard, Soil Till. Res., 144, 96-109, doi:10.1016/j.still.2014.07.010, 2014. 
Prasad, G. C., Mike, B., Adrian, B. L., Coles, N. A., and Lubczynski, M. W.: Reforesting severely degraded grassland in the Lesser Himalaya of Nepal: Effects on soil hydraulic conductivity and overland flow production, J. Geophys. Res.-Atmos., 118, 25282545, doi:10.1002/2013JF002888, 2013.

Price, K., Jackson, C. R., and Parker, A. J.: Variation of surficial soil hydraulic properties across land uses in the southern Blue Ridge Mountains, North Carolina, USA, J. Hydrol., 383, 256268, doi:10.1016/j.jhydrol.2009.12.041, 2010.

Reszler, C. and Fank, J.: Unsaturated zone flow and solute transport modelling with MIKE SHE: model test and parameter sensitivity analysis using lysimeter data, Environ. Earth Sci., 75, 253, doi:10.1007/s12665-015-4881-x, 2016.

Shang, Z. H., Feng, Q. S., Wu, G. L., Ren, G. H., and Long, R. J.: Grasslandification has significant impacts on soil carbon, nitrogen and phosphorus of alpine wetlands on the Tibetan Plateau, Ecol. Eng., 58, 170-179, doi:10.1016/j.ecoleng.2013.06.035, 2013.

Shein, E. V.: Soil hydrology: Stages of development, current state, and nearest prospects, Euras. Soil Sci., 43, 158-167, doi:10.1134/S1064229310020055, 2010.

Strudley, M. W., Green, T. R., and Ascough, J. C.: Tillage effects on soil hydraulic properties in space and time: State of the science, Soil Till. Res., 99, 4-48, doi:10.1016/j.still.2008.01.007, 2008.

Sun, M., Zhang, X., Huo, Z., Zhang, X. L., Huo, Z. L., Feng, S. Y., Huang, G. H., and Mao, X. M.: Uncertainty and sensitivity assessments of an agricultural-hydrological model (RZWQM2) using the GLUE method, J. Hydrol., 534, 19-30, doi:10.1016/j.jhydrol.2015.12.045, 2016.

Tatsumi, K. and Yamashiki, Y.: Effect of irrigation water withdrawals on water and energy balance in the Mekong River Basin using an improved VIC land surface model with fewer calibration parameters, Agr. Water Manage., 159, 92-106, doi:10.1016/j.agwat.2015.05.011, 2015.

Vereecken, H., Huisman, J. A., Franssen, H. J. H., Bruggemann, N., Bogena, H. R., Kollet, S., Javaux, M., van der Kruk, J., and Vanderborght, J.: Soil hydrology: Recent methodological advances, challenges, and perspectives, Water Resour. Res., 51, 2616-2633, doi:10.1002/2014WR016852, 2015.

Wang, G. X., Wang, Y. B., Li, Y. S., and Cheng, H. Y.: Influences of alpine ecosystem responses to climatic change on soil properties on the Qinghai-Tibet Plateau, China, Catena, 70, 506-514, doi:10.1016/j.catena.2007.01.001, 2007.

Wang, G. X., Liu, G. S., and Li, C. J.: Effects of changes in alpine grassland vegetation cover on hillslope hydrological processes in a permafrost watershed, J. Hydrol., 444, 22-33, doi:10.1016/j.jhydrol.2012.03.033, 2012.
Wang, Y. B., Wang, G. X., Wu, Q. B., Niu, J. F., and Chen, H. Y.: The Impact of Vegetation Degeneration on Hydrology Features of Alpine Soil, J. Glaciol. Geocryol., 32, 989-998, 2010.

Wei, Q., Wang, F., Chen, W. Y., Zhu, L., Li, G. Y., and Qi, D. C.: Soil physical characteristics on different degraded alpine grasslands in Maqu county in upper Yellow River, Bull. Soil Water Conserv., $30,16-21,2010$.

Wu, G. L., Liu, Z. H., Zhang, L., Chen, J. M., and Hu, T. M. : Longterm fencing improved soil properties and soil organic carbon storage in an alpine swamp meadow of western China, Plant Soil, 332, 331-337, doi:10.1007/s11104-010-0299-0, 2010.

Wu, Y. B., Zhang, J., Deng, Y. C., Wu, J., Wang, S. P., Tang, Y. H., and Cui, X. Y.: Effects of warming on root diameter, distribution, and longevity in an alpine meadow, Plant Ecol., 215, 1057-1066, doi:10.1007/s11258-014-0364-5, 2014.

Xiong, Y. Q., Wu, P. F., Zhang, H. Z., Cui, L. W., and He, X. J.: Dynamics of soil water conservation during the degradation process of the Zoigê Alpine Wetland, Acta Ecol. Sin., 31, 5780-5788, 2011.

Yi, X. S., Li, G. S., and Yin, Y. Y.: The impacts of grassland vegetation degradation on soil hydrological and ecological effects in the source region of the Yellow River-A case study in Junmuchang region of Maqin country, Proced. Environ. Sci., 13, 967-981, doi:10.1016/j.proenv.2012.01.090, 2012.

Yu, M., Zhang, L., Xu, X., Feger, K. H., Wang, Y., Liu, W., and Schwaerzel, K.: Impact of land-use changes on soil hydraulic properties of Calcaric Regosols on the Loess Plateau, NW China, J. Plant Nutr. Soil Sci.,178, 486-498, doi:10.1002/jpln.201400090, 2015

Zedler, J. B. and Kercher, S.: Wetland resources: Status, trends, ecosystem services, and restorability, Annu. Rev. Environ. Resour., 30, 39-74, doi:10.1146/annurev.energy.30.050504.144248, 2005.

Zeng, C., Zhang, F., Wang, Q. J., Chen, Y. Y., and Joswiak, D. R.: Impact of alpine meadow degradation on soil hydraulic properties over the Qinghai-Tibetan Plateau, J. Hydrol., 478, 148-156, doi:10.1016/j.jhydrol.2012.11.058, 2013.

Zhang, Z., Hu, H. C., Tian, F. Q., Hu, H. P., Yao, X. H., and Zhong, R. S.: Soil salt distribution under mulched drip irrigation in an arid area of northwestern China, J. Arid Environ., 104, 23-33, doi:10.1016/j.jaridenv.2014.01.012, 2014.

Zimmermann, B. and Elsenbeer, H.: Spatial and temporal variability of soil saturated hydraulicconductivity in gradients of disturbance, J. Hydrol., 361, 78-95, doi:10.1016/j.jhydrol.2008.07.027, 2008. 